\title{
Políticas educacionais e o avanço da nova (ou extrema?) direita
}

\author{
Jorge Fernando Hermida' \\ Universidade Federal da Paraíba, Programa de Pós-graduação em Educação, Mestrado \\ Profissional em Gestão em Organizações Aprendentes, Professor. \\ https://orcid.org/0000-0003-1963-4639 \\ Paulino José Orso² \\ Universidade Estadual do Oeste do Paraná, Professor associado. \\ https://orcid.org/0000-0001-9126-3276
}

\section{APRESENTAÇÃO}

É com grande alegria que apresentamos aos leitores o dossiê intitulado "Políticas educacionais e o avanço da nova (ou extrema?) direita". Trata-se de uma proposta acadêmica, mas também política e militante, que objetiva debater e problematizar sobre as mudanças políticas ocorridas nos últimos anos, não só no Brasil, mas também em outros países da América Latina e do mundo, focando em um tema em particular: o das políticas públicas educacionais, face ao avanço da nova (ou extrema?) direita.

0 dossiê trata de um tema que não é estranho aos brasileiros, pois o avanço da extrema direita e suas particularidades estão presentes todos os dias na pauta de variados jornais (impressos, televisados e/ou virtuais), nas mídias sociais e até em situações quotidianas, como no diálogo entre pessoas nos mais diversos âmbitos da sociedade.

Para tratar do assunto, convidamos renomados professores brasileiros e estrangeiros a colaborar, pensadores cujos aportes críticos têm contribuído, sobremaneira, para a compreensão das problemáticas contemporâneas vinculadas ao avanço de uma perspectiva política - a extrema direita - que é unanimemente considerada, em todos os nossos textos, predatória dos direitos e interesses da classe trabalhadora, da democracia e dos setores desfavorecidos e marginalizados da nossa sociedade.

Pós-doutor pelo Departamento de Sociologia e Comunicação da Universidade de Salamanca, Espanha; Doutor em Educação pela Universidade de Campinas.

2 Pós-doutor em Educação pela Universidade Estadual do Rio de Janeiro; Doutor em Educação pela Universidade Estadual de Campinas. 
Do ponto de vista político, o avanço da extrema direita no Brasil é decorrente do golpe jurídico-midiático-parlamentar ocorrido no ano de 2016, que, após destituir uma Presidente legítima e democraticamente eleita (Dilma Vana Rousseff), institui Michel Temer na Presidência da República. Com a usurpação do poder decorrente do Golpe de 2016, iniciouse um processo de reversão neocolonial, materializando reformas que culminaram na desconstrução de conquistas históricas, muitas delas garantidas na Constituição de 1988. Dentre as reformas mais importantes, destacamos a reforma trabalhista, o processo de privatização do Estado e a venda de riquezas naturais ao capital internacional.

A reversão neocolonial se intensifica assim que Jair Messias Bolsonaro se torna Presidente da República, em $1^{\circ}$ de janeiro de 2019. Como corolário do avanço, da assim chamada nova ou extrema direita, presenciamos ataques frontais e ainda mais profundos aos direitos arduamente conquistados pela classe trabalhadora e pela população em geral, ataques dos mais perversos, de toda ordem e em todas as frentes da sociedade. Uma nova reforma da previdência é aprovada, mais setores públicos são privatizados, e o Poder Executivo ainda ataca brutalmente os servidores públicos, por meio da aprovação de emendas constitucionais (PECs) que ampliam os controles fiscais com gastos públicos vinculados a salários e benefícios sociais e da criação de uma tal "regra de ouro", que proíbe o endividamento público referente às despesas com salários, benefícios, aposentadorias e até com relação às contas de água e luz. Como já era previsível, o processo de reversão neocolonial também atinge em cheio a educação pública, conforme observaremos nos primorosos artigos que compõem este documento.

Chamada nos bastidores de Brasilia de "nova política", esses modos de conceber e fazer política se inspiram na orientação ideológica da extrema direita internacional: o ultraliberalismo. A "nova política" não é nova, tampouco se trata de um fenômeno isolado, pois ela vem sendo implementada em muitos países do mundo, dentre os quais se destacam: Estados Unidos da América, Itália, Polônia, Hungria, Grã-Bretanha e França, no hemisfério Norte. Mas também Argentina (durante o Governo de Maurício Marcri - 2015-2019), Colômbia, Peru, Chile, Equador, Paraguai, Brasil e Uruguai, no hemisfério Sul.

0 pano de fundo que orienta o avanço da extrema direita no Brasil e no mundo se apoia na ideia de que o modelo de fazer política das democracias liberais, estruturado na base de partidos políticos tradicionais e no equilibrio dos poderes governamentais do Estado moderno (Judiciário, Legislativo e Executivo) que estava vigente desde o fim da Segunda Guerra Mundial (1945), entrou em crise, entrou em franco colapso. Concomitantemente à perda de autoridade dos partidos políticos tradicionais, temos a emergência de novos sujeitos políticos, que buscam impor uma nova lógica no modo de fazer política, a partir da imposição 
de verdades ancoradas em discursos de natureza subjetiva e orientados pela lógica da dissociação cognitiva (DUNKER, 2020). ${ }^{3}$

No caso do Brasil, não se trata apenas da deflagração de uma crise política no modelo democrático liberal, motivada pela emergência de um partido e um líder de direita. Trata-se, também, de um novo projeto político para o Brasil, proposto pela elite que estava "adormecida" desde o fim da Ditadura Militar (FRANCISCO, 2020). Para a jornalista Mônica Francisco (2020, p. 4), é possível caracterizar esse movimento, pois “São saudosistas antipovo e antipluralidade, que não imaginam a coexistência dos sujeitos na sociedade senão por meio do autoritarismo ou pela produção de desigualdades." Fundamentado na ideologia ultraliberal, esse movimento procura radicalizar cada vez mais a política, ancorando-se em atitudes e decisões autoritárias que, no Brasil, a esta altura, beira o protofascismo.

A crise política vem sendo estudada por diversos autores, que tratam da ruptura das democracias liberais (CASTELLS, 2018), do fascismo e sua lógica política do "nós" e "eles" (STANLEY, 2018), de como as democracias morrem (LEVITSKY; ZIBLATT, 2018), dos alertas necessários que devemos ter para brecar o fascismo (ALBRIGHT, 2018), de como - Ur-Fascismo pode voltar sob as vestes mais inocentes (ECO, 2019), até do ódio à própria democracia (RANCIĖRE, 2014).

Ao tratar da crise da democracia liberal, o espanhol Manuel Castells (2018, p. 6) nos alerta do seguinte: "Trata-se do colapso gradual de um modelo político de representação e governança: a democracia liberal que se havia consolidado nos dois últimos séculos, à custa de lágrimas, suor e sangue, contra os Estados autoritários e o arbítrio institucional." Se bem que uma versão mínima desse modelo político democrático liberal consegue ser implantado no Brasil, uma vez que o País retoma suas liberdades civis e democráticas depois de mais de 20 anos de Ditadura Militar e começa a ser desconstruído com o Golpe de 2016. Com a ascensão do governo de extrema direita, ultraliberal e protofascista ${ }^{4}$ de Jair Messias Bolsonaro, em $1^{\circ}$ de janeiro de 2019, a vigência da democracia liberal fica seriamente comprometida.

3 Essa perspectiva gramatical procura fragmentar qualquer tipo de debate lógico e/ou racional. Por exemplo, se você diz ser feminista, o outro teria direito de dizer, desde sua subjetividade, que ele é machista (sic?!). No dizer de Dunker (2020, p. 6), trata-se de uma estratégia em espelho, já que "se você pode ser gay, eu posso votar em Bolsonaro" ou "se você pode ser democrata, então eu posso ser fascista."

4 No marco do presente texto, nos valeremos da definição de protofascismo revelada pelo advogado, sociólogo e militante dos Direitos Humanos Rubens Pinto Lyra (2020): "Denomina-se protofascismo determinados aspectos sociais, políticos e ideológicos do nazi-fascismo, que podem estar presentes, parcialmente ou na sua plenitude, conforme a situação poĺtica, inclusive na atualidade, e no Brasil. Advirta-se que o nazismo, na Alemanha, o fascismo, na ltália e o protofascismo alimentado pelo governo de extrema direita no Brasil somente se tornaram realidade em virtude do apoio decisivo - inicialmente reticente, depois entusiástico - que receberam do capital financeiro e dos políticos que representam os seus interesses, com o respaldo dos militares." 
Esta seção temática é composta por 11 artigos, uma entrevista e uma resenha. A proposta envolveu 23 autores, sendo uma autora uruguaia, um autor uruguaio-brasileiro, cinco argentinos e 16 autores brasileiros. 0s professores estrangeiros são pesquisadores de três universidades: Universidad de la República (Uruguai), Universidad Nacional de Quilmes e Universidad de Buenos Aires (ambas da Argentina). No caso do Brasil, são procedentes de três regiões diferentes - Nordeste, Sudeste e Sul -, abarcando nove instituições de Ensino Superior, a saber: Universidade Federal da Paraíba (UFPB) e Universidade Federal de Alagoas (UFAL) na região Nordeste; Universidade Estadual de Campinas (Unicamp) e Universidade Federal de Minas Gerais (UFMG), na região Sudeste; e Universidade Federal de Santa Catariana (UFSC), Faculdade de Educação Superior do Paraná (FESP/PR), Universidade Federal do Paraná (UFPR), Universidade Estadual do Oeste do Paraná (UNIOESTE) e Centro Universitário UNINTER, na região Sul.

Abrindo a seção temos o artigo de Dermeval Saviani (Unicamp) intitulado Políticas educacionais em tempos de golpe: retrocessos e formas de resistência. Nele, inicialmente, o autor discorre sobre a política educacional brasileira e a precarização da educação no País expressa na filantropia, na protelação, na fragmentação e na improvisação; mostra que os avanços conseguidos entre 2003 e 2014 foram interrompidos pelo golpe jurídico-midiáticoparlamentar consumado em 31 de agosto de 2016, com o impedimento da então Presidenta da República Dilma Rousseff, ao qual se seguiu um grande retrocesso expresso na Emenda 95, que congelou os investimentos em educação, inviabilizando as metas do PNE aprovado em junho de 2014, a reforma do ensino médio e o projeto autodenominado Escola Sem Partido. E, à guisa de conclusão, indica formas de resistência ao retrocesso, que vem se ampliando e se aprofundando com a posse do novo governo em $1^{\circ}$ de janeiro de 2019.

Na sequência, o artigo do uruguaio-brasileiro Jorge Fernando Hermida (UFPB) e do brasileiro Jailton de Souza Lira (UFAL), intitulado Quando fundamentalismo religioso e mercado se encontram: as bases filosóficas e ideológicas da Escola sem Partido. Os autores apresentam uma análise dos últimos acontecimentos históricos, políticos e sociais vinculados à emergência e à expansão do movimento Escola Sem Partido, estabelecendo um diálogo entre as proposituras do movimento e as nuances acontecidas na vida política e na economia brasileira e mundial. Tendo como questão norteadora Quais bases históricas, econômicas e políticas orientaram as ações e proposições do movimento Escola Sem Partido?, os autores alicerçam suas respostas na interpretação marxista da história. Isto é, valendo-se do materialismo histórico e dialético, os autores identificam as bases e pressupostos históricos, econômicos e políticos que sustentam as teses fundamentalistas e religiosas do movimento. Nas considerações finais, os professores concluem que a existência de movimentos como - Escola sem Partido está diretamente articulada a setores políticos de extrema direita no Brasil, que, semelhantemente ao que vem ocorrendo em outros países, têm como propósito a desconstrução dos fundamentos da democracia liberal. Ao adotar a ideologia ultraliberal e 
o fundamentalismo religioso dos evangélicos neopentecostais e da Renovação Carismática Católica, os defensores do movimento têm como finalidade última a formação de cidadãos submissos à lógica da classe dominante, submissos à lógica do grande capital.

Em seguida, Adriana Marrero (Universidad de la República - Uruguai), no artigo La educación saboteada y otras paradojas de los gobiernos de izquierda en Uruguay: una de las razones para el desencanto, analisa os paradoxos em torno da educação pública, laica e gratuita que se constituiu como um dos pilares sobre os quais o Uruguai foi construído desde o final do século XIX. Mesmo assim, até o ano de 1963 os estudos universitários eram realizados somente por filhos das elites do País. A partir dessa data, a oferta educacional começa a ser ampliada. Para a autora, era de se pressupor que, assim que chegassem ao poder, no ano de 2005, os governos de esquerda investissem pesado para superar os históricos problemas educacionais. De fato, investiram: houve melhoras orçamentárias, investimento em infraestrutura e conquistas salariais, mas não foi o suficiente, uma vez que dados quantitativos indicam que um terço dos jovens uruguaios não conseguem completar - Ensino Médio. Apelando a um relato histórico para entender o presente, a autora conclui que é possível identificar paradoxos no discurso das autoridades de esquerda, pois impõem uma visão desvalorizada da educação e deixam margem para que os partidos de direita conquistem cada vez mais adesão da população - mesmo que seu discurso apresente uma mensagem autoritária e vitimizada que diz desejar ser restaurada.

No texto denominado Análisis comparativo de las estratégias políticas desplegadas desde los gobiernos petistas y kirchneristas, Javier Balsa (Universidad Nacional de Quilmes Argentina) se fundamenta na teoria da hegemonia de Gramsci e incorpora contribuições de Ernesto Laclau sobre populismo, para comparar as estratégias políticas levadas adiante pelos governos petista e kirchnerista, no Brasil e na Argentina, respectivamente, considerando seus limites e possibilidades.

Soraya Franzoni Conde (UFSC) e Maurício Roberto da Silva (UFSC), por sua vez, no artigo "Trabalho infantil ou exploração do trabalho infantil": reflexões e perguntas no âmbito da "persistência" do problema, debruçam-se perante esse controvertido assunto, com o intuito de contribuir para o debate na academia e, principalmente, nos processos de formação inicial e continuada de professores, movimentos sociais e sindicais, famílias, gestores e formadores. Analisam os conceitos de trabalho infantil e de exploração do trabalho infantil, a fim de desfazer possíveis confusões conceituais, etimológicas, epistemológicas e ideológicas, para, assim, poder possibilitar uma proposta de formação crítica das crianças.

Em Da família na escola à escola no lar, a Professora Maria Eulina Pessoa de Carvalho (UFPB) examina contextos, conceitos e discursos envolvidos na polêmica educação domiciliar e no Escola Sem Partido e conclui que a defesa do suposto direito dos pais a que seus filhos tenham uma educação em conformidade com suas crenças e convicções se 
revela como um atentado aos valores democráticos e aos direitos de cidadania, além de deslegitimar a educação pública e eliminar o pluralismo da vida pública.

No artigo A contrarreforma do Ensino Médio e as perdas de direitos sociais no Brasil, as Professoras Adriana Duarte, Juliana Batista dos Reis, Licínia Correia e Shirlei Sales - todas da UFMG - buscam identificar, descrever e analisar os processos e os efeitos da contrarreforma do Ensino Médio, regulamentada pela Lei n. 13.415/17, e a consequente perda de direitos sociais, especialmente para a juventude brasileira. A última etapa da Educação Básica tem sido alvo de reformas nas últimas duas décadas, propostas pelos governos nacionais ou pelos próprios estados federativos, responsáveis constitucionalmente por essa etapa da educação básica. Após analisar diversos dispositivos legais, e também diversas pesquisas desenvolvidas na área, as autoras consideram que a flexibilização imposta para esse setor de ensino reduz a Educação Básica à preparação para o mercado de trabalho, restringe e abrevia a oferta, amplia as desigualdades educacionais e oferece base legal para a privatização do ensino público; além disso, que o uso do conceito de contrarreforma potencializa a análise dos processos regressivos aos avanços dos direitos sociais diante dessa iniciativa. As autoras concluem o seguinte: a contrarreforma do Ensino Médio, ao invés de resolver questões históricas e estruturais vivenciadas pela educação pública, se efetivada, aprofundará as desigualdades sociais, escolares e regionais existentes em nossa sociedade.

Em seguida, temos dois artigos que discutem as políticas educacionais no período denominado neoliberal. 0 primeiro, de autoria de Geraldo Balduino Horn (UFPR), Ademir Aparecido Pinhelli Mendes (UNINTER) e Edson Teixeira de Rezende (FESP/PR), denominado As políticas neoliberais e o pragmatismo gerencial na educação pública paranaense, analisa as políticas educacionais levadas a cabo no Paraná, após o ataque ao funcionalismo público desferido em 2015 pelo Governador Beto Richa, depois do golpe que derrubou a Presidenta Dilma Rousseff, em 2016, e a partir de 2019, com o Governador Ratinho Jr. Ao longo de todo esse período aparece com destaque a defesa da privatização, tanto da educação quanto das instituições e dos serviços públicos. De acordo com os autores, além de terem destruído significativamente o plano de carreira dos professores, o trabalho pedagógico e as condições da produção docente, em decorrência das políticas iniciadas pelos últimos governos, com os ataques aos direitos dos servidores, em especial aos professores, a repressão "histórica" e a indiferença da justiça e do governo colocaram o Paraná entre os estados mais violentos da federação. 0 segundo artigo, de autoria de Ana Cláudia da Silva Rodrigues (UFPB), intitulado Redes de política de educação integral da Paraíba: fluxos e influências neoconservadoras e neoliberais, tem como lócus o Programa de Educação Integral do Estado da Paraíba e analisa o contexto da influência e da produção das políticas para a educação integral e as novas redes de governança implementadas pelo Estado. 
Paulino José Orso (Unioeste), por sua vez, em seu artigo denominado Elitização da universidade brasileira em perspectiva histórica, tece sua análise sobre a temática, discorrendo sobre a elitização do ensino superior, observando como surgiu a universidade no Brasil, a proposta idealizada pelos que a criaram, as mudanças pelas quais foi passando, o breve período de popularização e, por fim, os ataques a ela desferidos após o Golpe que derrubou a Presidente Dilma Rousseff, continuando nos governos de Michel Temer e de Jair Bolsonaro, com a finalidade de privatizá-la, para destiná-la a um punhado de privilegiados, ou seja, reservando-a a uma pequena "elite intelectual".

No texto Politicas universitarias en Argentina: Sistema Nacional de Docentes Investigadores Universitarios en la mira, os Professores argentinos Mariángela Nápoli, Judith Naidorf, Guido Riccono e Daniela Perrotta (todos da Universidad de Buenos Aires - Argentina), debatem sobre o processo de desregulamentação e posterior regulamentação das políticas universitárias vinculadas à pesquisa na República Argentina. Na opinião das autoras, não se trata de defender incentivos nem uma lógica apoiada na meritocracia, mas o governo argentino deveria buscar uma solução para os problemas e debilidades existentes, dentre eles a precarização do trabalho docente.

A seção temática se completa com uma entrevista e uma resenha. Jorge Fernando Hermida (UFPB) e Jailton de Souza Lira (UFAL) entrevistam o Professor Gaudêncio Frigotto (UERJ) sobre o atual momento conjuntural (política, economia e sociedade) de avanço da nova direita e do conservadorismo e seus desdobramentos nas políticas educacionais e a educação em particular. As perguntas abordam temas polêmicos, como: Escola Sem Partido; educação domiciliar; (des)financiamento da educação; fundamentalismo religioso; desconstrução das universidades federais e da educação pública; bem como as alternativas de luta contra o fascismo e o fundamentalismo ideológico e religioso. A resenha que fecha a proposta de dossiê temático foi feita pelo Professor Armando Boito Jr. (Unicamp) sobre o livro Poder político e classes sociais, de Nicos Poulantzas. Publicado pela Editora da Unicamp no ano de 2019, o livro tem como objetivo polêmico desenvolver a teoria política marxista, a partir do conceito ampliado de modo de produção, desenvolvido pela escola althusseriana. 0 autor da resenha destaca duas principais contribuições do livro: 1. A análise da estrutura do Estado capitalista e os efeitos ideológicos dessa estrutura. 2. 0 conceito de bloco no poder e os seus conceitos correlatos de fração burguesa e de hegemonia. Segundo Armando Boito Jr., tais contribuições enriquecem a análise da política nas modernas sociedades capitalistas.

Diante do exposto, convidamos os leitores a se debruçarem perante nossa proposta editorial, com a expectativa de que os diversos textos e autores contribuam para uma melhor compreensão da realidade política, social e cultural. 


\section{REFERÊNCIAS}

ALBRIGHT, M. Fascismo. Um alerta. São Paulo: Planeta, 2018.

CASTELLS, M. Ruptura: a crise da democracia liberal. Rio de Janeiro: Zahar, 2018.

DUNKER, C. I. L. Diário do ano da peste. Le Monde Diplomathique Brasil, ano 13, n. 152 mar. 2020.

ECO, U. 0 fascismo eterno. 6. ed. Rio de Janeiro: Record, 2019.

FRANCISCO, M. É possível sair deste abismo? Le Monde Diplomathique Brasil, ano 13, n. 152 mar. 2020.

LEVITSKY, S.; ZIBLAT, D. Como as democracias morrem. Rio de Janeiro: Zahar, 2018.

LYRA, R.P. 0 protofascismo brasileiro. Carta Maior - 0 Portal da Esquerda, 31 mar. 2020. Disponível em: https://www.cartamaior.com.br/?̣/Editoria/Antifascismo/0-protofascismo-brasileiro/47/47000 Acesso em: 2 jun. 2020.

RANCIĖRRE, J. 0 ódio à democracia. São Paulo: Boitempo, 2014.

STANLEY, J. Como funciona o fascismo. A politica do "nós" e "eles". Porto Alegre: L\&PM, 2018. 